\title{
How Cognitive Behavioural Therapy Helps on Addictive Behaviour?
}

Yusni Mohamad Yusop, Mohd Huzaini Husin, Zaida Nor Zainudin, Wan Norhayati Wan Othman, Maizatul Mardisna Harun, Melati Sumari, Nurul Nadia Abdul Ghafar

To Link this Article: http://dx.doi.org/10.6007/IJARBSS/v11-i12/11836

DOI:10.6007/IJARBSS/v11-i12/11836

Received: 10 October 2021, Revised: 12 November 2021, Accepted: 25 November 2021

Published Online: 17 December 2021

In-Text Citation: (Yusop et al., 2021)

To Cite this Article: Yusop, Y. M., Husin, M. H., Zainudin, Z. N., Othman, W. N. W., Harun, M. M., Sumari, M., \& Ghafar, N. N. A. (2021). How Cognitive Behavioural Therapy Helps on Addictive Behaviour? International Journal of Academic Research in Business and Social Sciences, 11(12), 995-1009.

Copyright: (c) 2021 The Author(s)

Published by Human Resource Management Academic Research Society (www.hrmars.com)

This article is published under the Creative Commons Attribution (CC BY 4.0) license. Anyone may reproduce, distribute, translate and create derivative works of this article (for both commercial and non0-commercial purposes), subject to full attribution to the original publication and authors. The full terms of this license may be seen

at: http://creativecommons.org/licences/by/4.0/legalcode

Vol. 11, No. 12, 2021, Pg. 995 - 1009

Full Terms \& Conditions of access and use can be found at http://hrmars.com/index.php/pages/detail/publication-ethics 


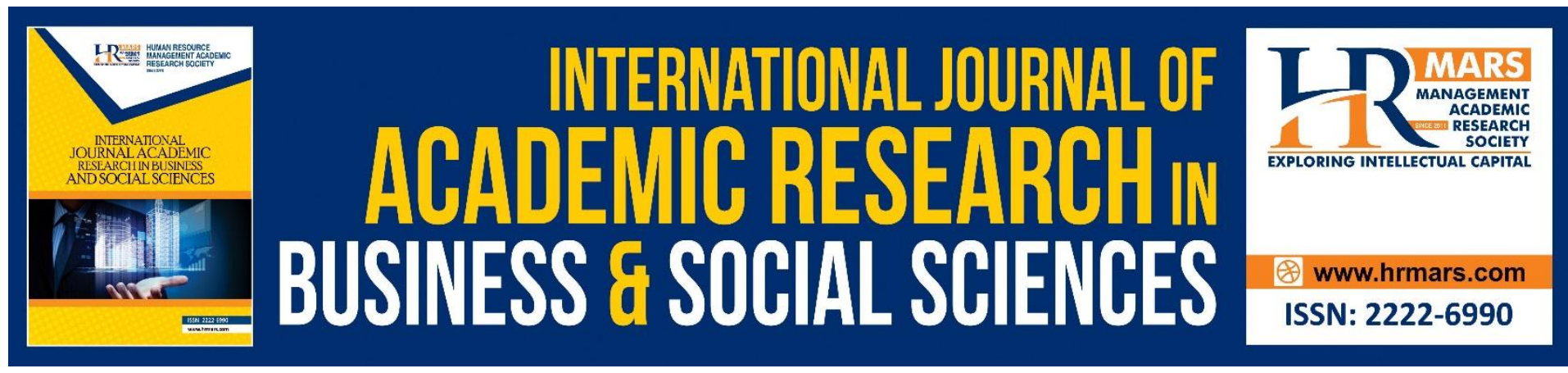

\title{
How Cognitive Behavioural Therapy Helps on Addictive Behaviour?
}

\author{
Yusni Mohamad Yusop (Ph.D), Mohd Huzaini Husin, Zaida Nor \\ Zainudin (Ph.D), Wan Norhayati Wan Othman (Ph.D), Maizatul \\ Mardisna Harun (Ph.D)
}

Faculty of Educational Studies, Universiti Putra Malaysia, Serdang Selangor Malaysia.

\author{
Melati Sumari (Ph.d)
}

Faculty of Education Universiti Malaya, Malaysia.

\section{Nurul Nadia Abdul Ghafar}

Faculty of Educational Studies, Universiti Putra Malaysia, Serdang Selangor Malaysia

\begin{abstract}
One of the well-known theories applied in the group counselling session is Cognitive Behavioural Therapy (CBT). This article explores the systematic literature reviews on the benefit of using CBT in group counselling among clients who were having issues with drugs. This systematic literature review is managed through the following Preferred Reporting Items for Systematic Reviews and Meta Analyses (PRISMA) guidelines. The Emerald, ProQuest Electronic and Cambridge University Press are used. This research utilized the Google Scholar website too. The term "drug", "abuse", "effect", "group counselling" and other relevant derivations used in web searching. Only 10 most relevant journal articles were extracted and reviewed. Findings showed that there were positive effects of CBT in group counselling on drug abused group members. The findings suggested that Cognitive Behavioural Therapy is effective in changing the perceptions and behaviours of drug addicts, controlling anger and increasing self-esteem. CBT may raise the sense of self-awareness as well as increased confidence not to relapse after they have been released from the rehab centre. Application of CBT in group counselling helped counsellor to propose the action plan properly, which involves several steps such as identifying the level of client motivation, risky situations, client relapse processes, client situations in making irrelevant decisions, cognitive factors related to relapse, and lifestyle changes. In conclusion, it is proved that group counselling benefits in accordance with CBT application during the session to help clients have a better view of life after they recover from drug addiction.
\end{abstract}

Keywords: Drug Abuse, Effect, Cognitive Behavioural Therapy, Group Counselling, Behaviour 


\section{Introduction}

The eradication of drugs in Malaysia began in the 1950s with the implementation of the Dangerous Drugs Act 1952. In fact, based on the data released by the National Anti-Drug Agency (AADK) annually, the cases of drug abuse among Malaysian youths are constantly increasing from year to year. Therefore, actions such as enforcement, rehabilitation, treatment, coordination, prevention and research have been generated to help the country eradicate its number one enemy. Drugs have been declared the country's number one enemy by Tun Dr. Mahathir bin Mohamad, Former Prime Minister of Malaysia on 19th February 1983 in conjunction with the National Anti-Drug Day celebration. Consequently, the National Drug Council and the National Anti-Drug Agency were established by the government. Now the symptoms of drug abuse are no longer just a national problem, but a global problem. If it continues then surely the future of the country, especially the future of young leaders will continue to be destroyed, crimes continue to be rampant and detrimental to health due to the lack of concerns over the spread of AIDS and HIV. Therefore, one of the actions seen as effective in helping drug addicts to rebuild their identity from being trapped in drugs is by engaging them with group counselling activities. This issue is the main focus in this article where the researcher reviews the impact of Cognitive Behavioural Therapy (CBT) towards drug addicts in group counselling.

Cognitive Behavioural Therapy (CBT) is an action-based psychosocial therapy in which human feelings and behaviours are influenced by how one thinks and not by external factors. Wrong thoughts lead to wrong behaviours and emotions. Among the CBT approaches are Rational Emotive Behaviour Therapy (REBT), Cognitive Therapy (CT), Dialectical Behaviour Therapy (DBT) and others. In the implementation of group counselling, the goal of behavioural cognitive therapy is to educate members on the role of maladaptive thinking in behaviour to prevent recurrence. Furthermore, it helps them to identify their thinking as well as learn skills to challenge inaccurate thinking and replace it with more accurate than REBT to eliminate irrational belief systems through the reorganization of the cognitive system using the A-B-C model.

The role of the group leader or counsellor in group counselling using Cognitive Behavioural Therapy is very important. Leaders need to be active in the group by triggering group members' perceptions and changing their thinking and allowing them to express the hidden feelings. Group members need to be taught on the background of emotional and cognitive skills to encourage members in helping each other to think more rationally. Group members also need the supportive atmosphere that may encourage their optimistic views. Positive thinking may help them to overcome problems that they are facing (Yusni et al., 2018). The concept "learning from others by observation and understanding their feeling" will allow group members explore themselves and make changes.

Additionally, Lee et al (2014) proposed that there are several ways to increase the effectiveness of group counselling based on key factors such as the process of self-disclosure that the individuals talk about themselves such as interests, feelings, beliefs, and attitudes to others. The supportive atmosphere throughout the session has a positive effect such as therapeutic, unconditional acceptance, non-punishment, empathy, authenticity, supportive and others. Group leaders moreover need to master all group skills to improve the quality of leadership. Group norms are also important, namely rules on appropriate behaviour during 
counselling sessions such as time management, attendance, active, interacting with each other, giving feedback and being open-minded. Every member of the group should have the hope that change is possible and should try to change for the better. Group members should also be catharsis, which is the process of expressing all latent feelings. Through the process of catharsis, the feelings expressed can be clearly associated with the experience and this is a tool for the individual to change. Elements of intimacy can also be included if necessary but should not be so extreme that it interferes with counselling sessions.

\section{Literature Review}

The implementation of group counselling shows some positive impact on the counsellors and clients involved. Among them is to improve the communication skills of group members. This will expose the members to the effectiveness in communicating not only with other members, but also the community. In addition, Yusni et. al (2020a) stated that the process of group counselling will not only bring a one-way approach that is counsellor to the client but, it also involves the client's approach to other clients, as well as the client to the counsellor. This creates a varied solution. Not only group counselling, the intervention used by the counsellor plays a role too to enhance the impact of the treatment. There are approaches applied by counsellor in group counselling, such as Cognitive Behavioural Therapy.

The basic concept of CBT is the thoughts and feelings that play a role in shaping behaviour. For example, the therapy can be used when a person is often anxious to think of a plane crash or a disaster that may occur through their journey. As a result, by using CBT, it able to change the new way of thinking that is more positive and emotionally stable as well as giving them the courage to board the plane without worry or hesitation (Yusni et al., 2020b). An action or behaviour has occurred as the result of new thoughts and more stable emotions. Nowadays, CBT is gaining popularity due to the existence of many cases of mental health, anxiety, anger, disorders, addiction, depression, substance abuse and panic attacks. Cognitive Behavioural Therapy helps in treating a variety of problems including phobias, panic attacks, along with addiction to drugs, cigarettes, and alcohol. Additionally, it also helps in treating disorders such as sleeping, eating, personality, obsessive, compulsive, and bipolar disorders. Furthermore, it is also found to be helpful in treating chronic pain, schizophrenia, dysmorphic body disorder, marriage and divorce problems, seasonal affective disorder, fibromyalgia and a lot more. The purpose is to teach patients that although they cannot control every aspect around them, they can control how to interpret and deal with things in their environment using new thinking and thoughts.

The use of Cognitive Behavioural Therapy (CBT) in group counselling is a relatively flexible approach and can be adapted to a variety of situations (Yusni et. al., 2020c). Group members will learn new skills such as coping skills and interpersonal skills with other members. It can address the issue of drug addiction and also the problem of relapse that they will face when they finish their treatment program at the treatment centre. Patients who are undergoing rehabilitation and treatment can also combine CBT with other treatment methods such as career counselling, expression therapy (music, art, acupuncture, and yoga) and pharmacotherapy treatments such as methadone treatment. Pharmacotherapy is the treatment of pain through the use of drugs through the diagnosis, prevention and cure of diseases. Through this combination, treatment can have a positive effect in the long run. 
Among the theoretical methods of cognitive behaviour that help drug addiction are by empowering patients, for instance to:

- $\quad$ Provide simple methods and techniques in changing their negative thoughts.

- $\quad$ Build up the confidence and will of their goals in the issue of drug addiction.

- Help them imagine the future positively.

- $\quad$ Help them increase strength and more positive relationships.

- $\quad$ Assist them in dealing with relapse problems.

- $\quad$ Assist them in opening up space in activities that are more meaningful than activities that allow them to relapse into drug addiction.

\section{Objective}

The aim of this article is:

- To discuss the effectiveness of Cognitive Behavioural Approach in helping drug abuse in group counselling.

\section{Methodology}

The keywords "CBT", "group counselling", "drug abuse", "behaviour" and "effective" during 2013-2020 produced 51 articles and reviews. The number of results found was decreased by keywords "approach", "CBT Theory" and "drug abused". Then, filtration was then being conducted by limiting the search results into articles which are related to psychology, social science and arts and humanities. Researchers narrow down the search results only to social field research. The search excluded the medicine and nursing field article, the literature review, books and book chapter. The search was stopped when 10 most relevant journal articles were found. The selected articles had been downloaded from the publication servers and saved in the form of PDF files. The articles were studied and reviewed thoroughly.

\section{Inclusion Criteria}

All articles from various journals are from January 2013 to November 2019. This is considered as recent research data. Only research articles in the form of quantitative research are included in this systematic review. Moreover, articles selected can be either in Malay or English Language. Subject areas related to counselling are included, which are Psychology, Social Science and Arts and Humanities. The countries of the articles in this systematic review are from various countries such as Malaysia and Indonesia.

\section{Exclusion Criteria}

Researchers exclude the studies of qualitative research, reviews, book chapters and books. Subject areas like Laws, Pure Science, Economics, Econometrics, Finance, Business, Management, and Accounting, which are irrelevant to this area are excluded too.

The flow of the systematic review started with initial search using the terms group counselling, effectiveness, approach, and effects. The search was followed by including the year of publication, population, article type, and subject area. There were 51 papers found related to the key terms in the search. Only 38 of the papers were published from 2013 to 2019. The retrieved papers were screened based on their titles and abstracts. 23 of the papers were selected due to the subject area in psychology, social science, as well as art and humanities. Articles then narrowed down to 17 which included approaches and effects of 
group counselling. Finally, 10 relevant literatures were selected from different journal sources.

\section{Findings}

Based on the literature review of ten articles, results show that the approach of Cognitive Behavioural Therapy is effective in helping drug addiction issues. The findings are discussed in ten related articles as follows.

\section{Article 1}

Muhamamd (2016). The Effects of Behavioural Cognitive Therapy (CBT-B) Interventions on the Willingness to Change and Self-Esteem in Drug Rehab Institutes. Sintok: University Utara Malaysia.

According to Muhammad (2016), the effects of drug abuse are quite large on the country and more significant on the addicts themselves, especially on adolescents. Youth or adolescence is a phase between children and adults that generally refers to those aged between 15 years and 25 years old. Studies show that unsupervised youths and the attitude of not caring about children's social activities by family members can cause them to become addicted to drugs. Therefore, the efforts of various parties in the fight against drug abuse need to be strengthened comprehensively starting at the individual, family, and community level to the highest level. Thus, one of the best interventions in dealing with drug issues among adolescents is group counselling using Cognitive Behavioural Therapy as it is seen to be very effective in changing the perceptions and behaviours of drug addicts.

As a counsellor and leader of a counselling group that adopts a cognitive behaviour therapy approach, they have certain characteristics and strengths used in their practice such as;

- Empathy and kindness - counsellors have to deal with group members who have complex and difficult emotional problems especially in building successful therapeutic relationships.

- Excellent listening skills - Counsellors need to listen to each group member and understand the goals and values to solve the problem.

- Strong organizational skills - This is if the counsellor plans to start his own organization which covers payments, schedules and insurance companies.

- $\quad$ Communication skills - Counsellors need to work with group members from various cultures, backgrounds and belief systems. In addition, counsellors should always be sensitive to various ethnics' needs and various communication styles.

- $\quad$ Skills to create good relationships - Counsellors need to have good relationships and have the ability to solve complex problems in relationships with group members.

\section{Article 2}

Ade (2019). Approaches to Cognitive Behaviour Therapy in counselling services for victims of drug abuse at the House of Serenity, Bandar Lampung. Universitas Negeri Raden Intan Lampung Indonesia.

Ade (2019) stated that CBT is a form of psychotherapy that pays close attention to aspects in thinking, feeling and acting. The CBT techniques that can be used in group counselling are; 
- $\quad$ Bring rational confidence

- $\quad$ Re-discuss. For example, the issue of accepting internal emotional state is something that is worrying and frightening.

- $\quad$ Repeat a situation to the counsellor through role play activities.

- Use a variety of personal statements for different situations.

- Measure the range of feelings for example by placing the existing feelings of anxiety on a scale of 0-10.

- $\quad$ Stop thinking. Do not let anxious or obsessed thoughts "take over" yourself. For example, clients learn to stop thinking in other ways.

- $\quad$ Clients need to practice self-assertion.

- $\quad$ Systematic sensitivity. That is, he replaced the feelings of fear and anxiety with calm. Counsellors help clients eliminate negative to positive feelings.

- $\quad$ Homework method. Clients practice new thinking, behaviour and strategies.

- In Vivo Exposure. The client, along with the counsellor, overcomes the problem of fear through on-set reality, for example visiting an area that makes the client suffer or encounter extreme fear. The role of the counsellor is to motivate the client to use behavioural cognitive techniques to overcome the situation.

\section{Article 3}

Norzihan et al (2016). The effectiveness of cognitive behavioural group counselling on anger and aggression among male prisoners. Journal of Malaysian Psychological, 30 (1), 40-51.

Moreover, Norzihan et al (2016) said the cognitive behavioural group intervention based on anger management is one of the methods widely used for drug addicts in the prison system in the West, especially in the case of dealing with angry emotions. Group counselling which applies a cognitive behavioural theory approach can reduce dysfunctional behaviour and improve resilience strategies as well as aggressiveness on various populations such as prisoners, drug addicts, mental patients and sex prisoners. Moreover, the Theory of CBT in managing anger shows that it can control anger and increase self-esteem. A study by Norzihan and colleagues (2016) proved that cognitive behavioural group counselling promises positive effects especially in contributing to the process of rehabilitation of prisoners which focuses on crime rates such as drugs and others. In other words, a decrease in anger at the same time plays an important role in a decrease in drug intake among drug addicts.

\section{Article 4}

Nurdeng \& Nurfatin (2018). The effectiveness of drug treatment and recovery from residents' perspective at PENGASIH house, Bukit Tunku, Kuala Lumpur, Malaysia. South-East Asian Journal for Youth, Sports \& Health Education, 4(2).

Drugs are a universal problem. Based on Nurdeng et al. (2018) regarding the program held at PENGASIH House, Bukit Tunku, Kuala Lumpur, institutional drug treatment and rehabilitation programs have started since 1975 . This program is under the Ministry of General Welfare. In 1983 , when the government recognized drugs as a threat to national security, drug treatment and rehabilitation programs were entrusted under the Ministry of Home Affairs. A group counselling session conducted at this centre found that the treatment and rehabilitation programs carried out had an effect on drug addicts from continuing to be trapped in the drug scene. The group approaches methods used by drug addicts in PENGASIH House namely TC 
(Therapeutic Community), static group, peer confrontation, encounter, morning meeting and so on. It is all based on CBT that led to many changes in the formation of their values, attitudes and personalities, where a sense of self-awareness arises as well as increased confidence not to relapse when they have been released and want to build a more meaningful life.

\section{Article 5}

Nurfatin et al (2016). Drug treatment and rehabilitation programs at drug addiction rehabilitation centers, Kuala Lumpur. Malaysian Journal of Social Sciences and Humanities, $1(3)$.

Nurfatin et al (2016) explained the activities of drug treatment and rehabilitation programs at a treatment centre in Kuala Lumpur using the method of cognitive behaviour therapy group counselling approach has successfully helped counsellors in the drug rehabilitation process, especially in the aspect of behavioural reshaping and vocational life skills. The results of the study are used to support alternative drug rehabilitation programs of the treatment and rehabilitation of existing drug addicts in the country. At this centre, they have to join a supportive counselling group to undergo a process of forming more positive behaviours in terms of healthy emotions. In group sessions, they are exposed to negative attitudes, urging awareness and immediate change in behaviour and thinking. They will make group counselling as a social learning arena for each of its members by engaging and taking lessons from the experiences of all group members. In addition, the static group consisting of 7-8 members and supervised by counsellors aims to retrieve bitter personal events, issues and trauma in the group members' lives. All of these group counselling used a Cognitive Behavioural Therapy approach to ensure self-change in the thoughts and behaviours of drug addicts.

\section{Article 6}

Mohammad et al (2015). The Effect of Adolescent Adaptation Group Counselling on Resilience among At-Risk Adolescents in Drug Abuse. Department of Psychology and Counselling, Faculty of Education \& Human Development. Tanjung Malim, Perak: University Education Sultan Idris.

Mohammad et al (2015) stated that the main aspect is to highlight the concept of adolescents at risk of taking drugs and early intervention by emphasizing the process of development and prevention through Adolescent Adjustment Group Counselling (KKPR) in an effort to increase the level of resilience among adolescents. KKPR is based on the cognitive behavioural therapy theory group such as REBT which is found to be effective in the process of internal adjustment that covers aspects of thinking, feelings and behaviour among adolescents. Among the things that caught my attention were the results of the proposed action plan to identify and help atrisk adolescents who are taking drugs. Here is a series of action plans outlined by the writer;

- $\quad$ First, identify the marker system that is external characteristics (social) through the method of teacher's observation. Teachers observe it by identifying adolescents who have low academic achievement and less involvement in school activities such as often alone, not socialising and others.

- $\quad$ Secondly, administer the Instrument of at-Risk Taking Drugs Adolescent to identify the psychological characteristics of them such as low-level perception of family, self-esteem, depression and low resilience. 
- Third, build conducive relationships between teachers and students as well as encourage face-to-face interviews or explorations to identify negative experiences from the following social environments. The interviews involve parents, family members, teachers, peers, neighbours and others to identify problems.

- $\quad$ Fourth, perform interventions in the form of development and prevention such as empowering methods in teaching and learning, enhancing guidance programs for the purpose of personal and academic development process as well as mobilizing the counselling process more effectively such as individual counselling or group counselling. This is where the role of the theory is fully utilized.

- $\quad$ Fifth, implement the evaluation process quantitatively and qualitatively.

\section{Article 7}

Amin et al (2018). Handling relapse using cognitive behaviour therapy (CBT). Journal of Islamic Social Sciences and Humanities, 13, 39-47.

According to Amin et al. (2018), various government efforts and campaigns have been carried out to help address the problem of drug abuse. The increase in the number of drug addicts is not only due to the rising number of new drug addicts, but also the increasing number of those who become repeat addicts. This recurring addiction is due to relapse problems faced by those who have quit. Additionally, there are several triggers in which addicts feel "craving" and want to get addicted or take drugs again. Triggers can be in the form of people, places, situations and things. CBT introduces Relapses Prevention Techniques that involve several steps such as identifying the level of client's motivation, risky situations, client's relapse processes, client's situations in making irrelevant decisions, cognitive factors related to relapse and lifestyle changes.

As stated by Amin et al (2018), behavioural cognitive therapy (CBT) is a practice applied in counselling that suggests an approach to help with relapse problems among addicts. This therapy emphasizes "here and now" and also provides techniques to reduce the symptoms of addiction. According to a study conducted by Skinner, the reward system plays a role in an action determining the retention of a behaviour. Behavioural therapy also demonstrates methods of eliminating negative behaviours through fines or punishments. These therapeutic strategies focus on changing and enhancing the level of self-motivation, exploration of drugrelated behaviours by changing their lifestyles and behaviours. It also focuses on the interaction systems or styles of thinking, values of life, views, expectations and assumptions of corrupt thinking held by individuals. Individuals who practise this therapeutic treatment will identify and solve behavioural problems with various techniques (e.g., coping or craving) to stop taking drugs and manage problems that go along with drug abuse. The authors have formulated a technique based on cognitive behaviour therapy known as Relapse Prevention (RP). This RP method is part of the recovery process in exploring the behaviour and cognitive behaviour of drug addicts.

\section{Article 8}

Mohammad et al (2015). Effect of drug prevention program based on thought pattern modification (TPM) module towards resilience and aggression among risky youth. Journal of Anti-drug Malaysia, 9(1). 
To prevent is better than to cure and is the best method of reducing the cost of drug abuse. Thus, to realize this vision, modules were formed that are useful to counsellors, trainees, facilitators and group leaders to use by starting to implement them at the school level. Mohammad et al. (2015) stated that the Drug Prevention Program based on Thought Pattern Modification Modules (PCP) on resilience among at-risk youth such as drug abuse with a combination of PCP-oriented approach and behavioural cognitive therapy can help and reduce addictive rates of drugs in Malaysia. Accordingly, a prevention program through the exposure of a combination of mind-set modification approaches - behavioural cognitive therapy (PCP-TKT) has been developed. As an example, the ABC Model (A: Event, B: Belief, C: Effect) which is often used to analyse thoughts, behaviours and emotions. According to Thomas, Bateman, Simon, O'Grady and Carsell (2002), group interventions that incorporate cognitive behavioural approaches in group counselling are effective in reducing various behavioural problems such as substance abuse (drug), sexual activity, juvenile cases, delinquent activities and others. The module-based PCP-TKT group intervention presented by the authors proved to be successful in reducing the variabilities while strengthening resilience among youth.

The Cure \& Care service centre, Client Integration Centre and Caring Community House (CCH) is a daily activity centre for those who need services related to drug problems by offering outpatient packages, day care and inpatients. Most of the services offered are group counselling features such as social support groups and relapse prevention groups. A social support group is a safe discussion group for clients to re-practice their social skills. It also encourages and expands the support system and restores the client's social relationships with family members, peers and the community without clinical support. Through this session, the client learns the process of social interaction while the more experienced members will act as role models in this support group. The group will be led by a counsellor and divided into small discussion groups that will be led by a co-leader i.e., a facilitator or client who has been stable in his or her recovery. Usually, the time required is up to six months.

\section{Article 9}

Huzili \& Mohamad (2014). The effects of cognitive behavioural group therapy interventions for age category against self-esteem of drug addicts. Journal of Human Development and Communication, 3, 47-65.

Huzili and Mohamad (2014) conducted a study to look at the effects of cognitive behavioural group therapy for age categories divided into three, namely first, 19 to 29 years old $(n=34)$, second, 30 to 39 years old $(n=43)$ and third, 40 to 60 years old $(n=31)$. Thus, the difference in the pattern of change in mean scores for the three age categories is most likely due to the use of several CBT techniques that are quite effective throughout the intervention process. The CBT approach is characterized by 'Brief Counselling' because it is very important to structure the session and time period in conducting counselling sessions. Typically, the amount of the sessions is between 10 to 20 sessions and is categorized as CBT-Standard. But due to the present, most of them are busy working and constantly chasing time, CBT practitioners began to act by shortening the time period as needed. Thus, CBT-Brief was designed to shorten counselling sessions. The counselling sessions are less than 10 sessions that are easier, efficient and cost effective. 
According to Huzili and Mohamad (2014), the factors that contribute to the effectiveness of this group of CBT therapies are due to the input of modules that have been built by researchers that provide self-awareness, skills to increase self-esteem and focus of their internal control. In addition, the group counselling process that applies therapeutic relationships between counsellors with each other also has a positive effect. Systematic and structured group counselling methods as well as effective skills training help counsellors and trainees conducting interventions increase the total score.

\section{Article 10}

Mahzam (2013). The Effects of Cognitive Behavioural Approach in Group Counselling Towards Social Anxiety and Self Focus Attention Among Adolescents. Kuala Lumpur: University of Malaya.

Recognising the fact that adolescents are also part of the country's human resources and assets, Mahzam (2013) conducted a study to see the effect of cognitive behavioural approach in group counselling (PKTKK) on social anxiety and self-focused attention of adolescents. The treatment in this research is not really focused on the drug abuse issue, but the approaches used by the researcher are applicable to help the behavioural relapse towards drug addicts. Mahzam (2013) used group counselling modules in using behavioural cognitive approaches to ensure effective group counselling treatment. I was very interested in the group counselling treatment method she used since it was very clear. The time used for each module is one hour and 30 minutes for each group counselling session. Here is the essence and summary of the detailed module;

Session 1: (Introduction and Psychoeducation) - Build a rapport (Ice Breaking), rules of hope and consent, description and rationale of treatment, complete the survey inventory form and homework training for each group member.

Session 2: (Exposure training - Exposure) - Checking homework, questioning thinking inaccuracies, exposure sessions, training and distribution of exposure.

Session 3: (Cognitive restructuring training) - Reviewing homework, structured cognitive training, questioning and looking at thinking inaccuracies, giving rational responses and distribution of homework.

Session 4: (Relaxation training) - Reviewing homework, description of relaxation purpose, start relaxation exercise and homework distribution.

Sessions 5-7: (Combination of relaxation / exposure / cognitive restructuring) - Review of homework, relaxation exercises, exposure exercises (spontaneous speech), cognitive restructuring (spontaneous) and distribution of homework.

Session 8: (Termination) - Reviewing homework, reviewing progress, obtaining feedback throughout the group treatment session, setting goals for follow-up services if necessary, completing research forms and parting sessions.

CBT is a cognitive or rational thought process to see how clients think rationally in a taxonomy level of analysis which consists of understanding, knowledge, application, analysis, synthesis and evolution. Individuals who practise the cognitive process wisely are able to control maladaptive behaviour. The following is an example of a list of thinking errors as stated:

- Empty-or-All thinking is also known as black and white thinking, polar or dichotomous 
thinking (choice between two options only).

- $\quad$ Expect negative events that had, are and will occur.

- Making predictions of something bad will happen similar to a fortune teller.

- Inviting disaster, negative thinking of bad things that might happen.

- Denying or disqualifying positive things.

- Rationale is based on emotions because one firmly thinks it is right.

- $\quad$ Labelling yourself or others without proof leads to destruction.

- $\quad$ Mind screening or selective selection without looking at the whole.

- $\quad$ Reading the mind or not thinking about the possible thoughts of others.

- $\quad$ Excessive formulation or making outrageous negative perceptions.

- The "Need" and "Must" statements are also known as the statement of instructions.

- Misconceptions or illogical thoughts.

The principle of behaviour consists of learning that occurs consciously while habituation is formed unconsciously. Behaviour can be controlled by eliminating, increasing and decreasing frequency. Reinforcement and punishment are among those that can educate an individual to change behaviour from negative to positive. Behaviour can be seen from situational factors. Behaviour can be learned and can also be eliminated. Some key assumptions are as follows;

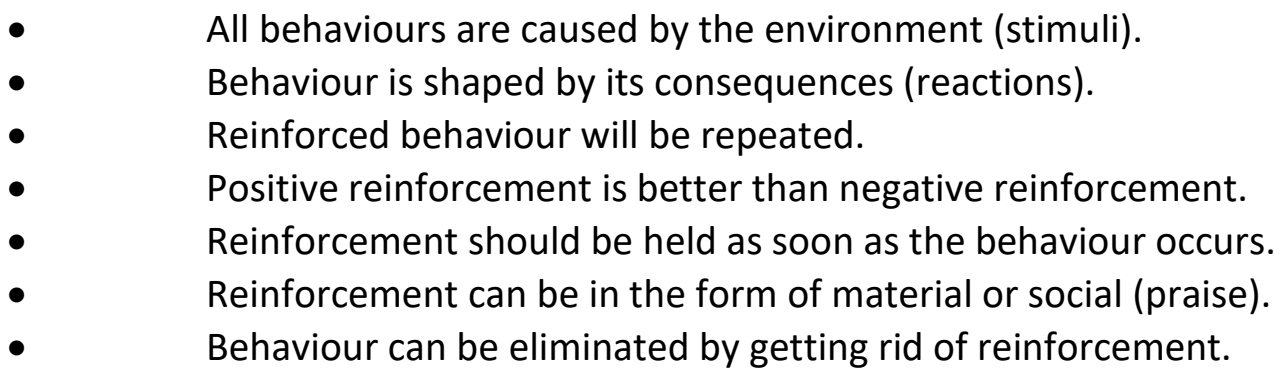

\section{Summary}

The pioneer of Cognitive Behaviour Therapy was Aaron T. Beck, a psychiatrist at the University of Pennsylvania. It is also based on the strategy of "identify, avoid and overcome" or "recognize, avoid and cope". It is to overcome desire and addiction by getting motivated, solving problems, planning and managing situations such as relapses. According to T. Beck, CBT will shape thoughts such as wearing glasses that make us see the world in a certain way (Corey, 2017). It creates an awareness of how and how this pattern of thinking creates reality as well as determines how the behaviour occurs while explaining that the interpretation and perception of a depressed person will be distorted. Individuals who are in a depressed state may be involved in assessing "cognitive errors" such as a negative-minded mind, constantly jumping to conclusions, trying to destroy and often thinking or getting a black and white picture. It is an automatic thought that comes spontaneously. Cognitive assessment errors lead to unhealthy behaviours.

It is highlighted that an advantage of implementing Cognitive Behavioural Therapy in group counselling is more effective than in individual therapy regarding the technique of homework. After listening to other members' homework reports, members can learn how to better address their issues. It also serves as a laboratory where behaviour can be monitored directly. 
Group setting provides the challenges like individuals need to review old patterns of dysfunctional behaviour and adopt healthier behaviours. Self-disclosure in group counselling sessions make members realize that it is worth a try. Apart from that, group members will observe various types of personalities and behaviours in the group counselling. The selfdisclosure done by group members will get feedback from other group members. This will encourage an individual to explore himself in different ways. Members have the opportunity to learn from the experiences of others, try to solve problems and be responsible throughout their life.

The use of group counselling using CBT in spiritual activities also shows positive changes in the thoughts, attitudes and behaviours of drug addicts. This is proven through the programs that have been conducted by AADK for the treatment and rehabilitation services of drug addiction involving the community. Among the programs and group counselling conducted based on religion or spirituality are fardhu ain' guidance group programs, state guidance, AlQuran guidance, moral and civic guidance, khotaman activities and halaqah groups implemented in small groups based on the clients' knowledge level by basic topics such as azan, prayer, basic of prayers, basic al-Quran and others. The Manaqib Ceremony was conducted in small groups by letting the drug addicts meet with family members while being led by a counsellor. All of this involves the purity of the heart which can cleanse the mind (cognitive) and soul as well as change negative behaviour to positive.

Group counselling is one of the approaches used in the treatment and rehabilitation process for prisoners. They are given the opportunity to share experiences, spaces, problems and feelings with each other to create the value of trust, repentance and resolve to be drug-free after being released from prison later. For prisoners who have been convicted, they must go through a process of treatment and rehabilitation through programs such as group counselling as prescribed according to the specific duration and phase. According to Mahmood (2006), based on the experience of ex-prisoners, group counselling approach is very effective and helps administer offenders in various issues and the behaviour of offenders allows management to execute appropriate actions to control the security and order of the prison.

Group counselling is seen as one of the most appropriate implementations in dealing with drug issues en masse. However, keep in mind that focusing on the wisdom of counsellors is very important in becoming the group counselling machinery. Moreover, in many theories available, Cognitive Behaviour Therapy (CBT) is the best and most suitable to be used to address the problem of drug abuse especially in this increasingly challenging new millennium era. Essentially, the CBT approach is to transform the psychology of drug addict thinking into productive stress and conflict management capabilities. Logically, drug addicts will say "No" to drugs, hate drugs, find other ways to replace drugs, build self-defence against drugs and others. This method will motivate and change the personality of drug addicts to positive behaviour. Efforts to treat and rehabilitate drug addicts need to be continued with effective procedures and treatments such as group counselling.

\section{Conclusion}

Those articles suggest that the CBT applied in group counselling are effective in helping clients. Group counselling members feel a sense of belonging since they can see that they are 
not the only people who have the problems. What is more, they learnt from other group members how to handle the issue in various approaches. The group members are exposed to make changes in their lives based on others' experiences. Group counselling teaches them that they are responsible towards their own life. From the CBT group counselling techniques applied by group leaders, group members learn how to change their ways of thinking. These changes bring new emotions and more positive behaviour.

Group leaders may allow other group members to help each other in multiple ways during group counselling sessions. Group members no longer need to isolate themselves. Group members need to realize that there is no need to have conflict with others, since everyone always has their own ways and choices. On top of that, they learn the struggles, the motivation and the strength from other group members.

In conclusion, CBT group counselling helps members to improve their way of thinking rationally. Positive thinking will affect the emotional state to be more stable. The rational thinking will bring positive behaviour as well. People will behave according to the belief system or what he thinks (mind setting). During counselling sessions or rehabilitation treatments, the client will learn to recognise the destructive or disturbing thought patterns, which always lead to negative influence on behaviour and emotions. Cognitive Behavioural Therapy can be an effective treatment option for a different psychological issue. CBT are recommended to apply in group counselling to help the cases of drug addiction.

\section{References}

Ade, S. M. (2019). Approaches to Cognitive Behaviour Therapy in counselling services for victims of drug abuse at the House of Serenity, Bandar Lampung. Universitas Negeri Raden Intan Lampung Indonesia.

Amin, A. S., Azad, A. A., Norsayyidatina, C. R., Wan, A. Z., Nurul, A. M., Musa, M. (2018). Handling relapse using cognitive behaviour therapy (CBT). Journal of Islamic Social Sciences and Humanities, 13, 39-47.

Asmah, I. (2018). Group counselling: The process, skills and issues. Nilai, Negeri Sembilan. University Sains Islam Malaysia.

Huzili, H., \& Mohamad, H. O. (2014). The effects of cognitive behavioural group therapy interventions for age category against self-esteem of drug addicts. Journal of Human Development and Communication, 3, 47-65.

Ida, H. A. T. (2006). Leading Group Counselling. PTS Professional: Kuala Lumpur, Malaysia.

Jamaludin, A. (2007). Drug Abuse Modules \& Counselling. Serdang: University Putra Malaysia. Lee, K. C., Ee, A. M., Suppiah, N., \& Taquddin, A. M. (2014). Children Guidance and Counselling. Selangor: Oxford Fajar Sdn Bhd.

Mahmood, N. M. (2006). Preventing, treating \& rehabilitating drug addiction: Some approaches and practices in Malaysia. Utusan Motivation and Excellence Series. Utusan Publications.

Mahzam, M. S. (2013). The Effects of Cognitive Behavioural Approach in Group Counseling Towards Social Anxiety and Self Focus Attention Among Adolescents. Kuala Lumpur: University Malaya.

Mohammad, A. S., Muzaffar, S., Abdul, M., Ahmad, J. J., Syed, S., Muhammad, B. M. (2015). Effect of drug prevention program based on thought pattern modification (TPM) 
module towards resilience and aggression among risky youth. Journal of Anti-drug Malaysia, 9(1).

Mohammad, N. B., Samsiah, M. J., Aslina, A., Amelia, M. N., Ahmad, J. J., Muhammad, B. M., Noraini, I., Faizura, R., Mohd, N. I. (2015). The Effect of Adolescent Adaptation Group Counselling on Resilience among At-Risk Adolescents in Drug Abuse. Department of Psychology and Counselling, Faculty of Education \& Human Development. Tanjung Malim, Perak: University Education Sultan Idris.

Muhamamd, S. M. Z. (2016). The Effects of Behavioural Cognitive Therapy (CBT-B) Interventions on the Willingness to Change and Self-Esteem in Drug Rehab Institutes. Sintok: University Utara Malaysia.

Norzihan, A., Rohany, N., Mohd, S., Nor, B. A. K. (2016). The effectiveness of cognitive behavioural group counselling on anger and aggression among male prisoners. Journal of Malaysian Psychological, 30 (1), 40-51.

Nurdeng, D., \& Nurfatin, A. M. M. (2018). The effectiveness of drug treatment and recovery from residents' perspective at PENGASIH house, Bukit Tunku, Kuala Lumpur, Malaysia. South-East Asian Journal for Youth, Sports \& Health Education, 4(2).

Nurfatin, A. M. M., Nobaya, A., Hanina, H. S. H. (2016). Drug treatment and rehabilitation programs at drug addiction rehabilitation centers, Kuala Lumpur. Malaysian Journal of Social Sciences and Humanities, 1(3).

Samihah, K., Siti, A. J. A. \& Rusniah, A. (2018). Kratom Plants in Malaysia. Challenges and prospects. Sintok: University Utara Malaysia.

Yusni, M. Y., Zaida, N. Z., \& Asmah, I. (2018). Effects of Group Guidance Activities on Students' Self-Concept. International Journal of Academic Research in Business and Social Sciences, 8(12), 1698-1706.

Yusni, M. Y., Zaida, N. Z., Wan, M. W. J., Wan, N. W. O., Dini, F. B., \& Nathynie, A. (2020a). The Effects of Group Counselling. Journal of Critical Reviews, 7(13), 623-628.

Yusni, M. Y., Norsyamimie, A.R., Zaida, N. Z., Asmah, I., Wan, N. W. O., Melati, S. (2020b). The Effectiveness of Cognitive Behavioural Therapy in Group Counselling. International Journal of Academic Research in Business and Social Sciences, 10(9), 359 - 379.

Yusni, M. Y., Zaida, N. Z., Nor, A. A., Wan, N. W. O., Shahlan, S., Wong, S. F. (2020c). The Effectiveness of Group Counselling: A Systematic Review. Journal of Critical Reviews, 7(13), 513-518. 